\title{
Translation: Bridging the Gap, or Creating a Gap to Bridge? Reflections on the Role of Translation in Bridging and/or Widening the Gap between Different Cultures with Particular Reference to Religion and Politics
}

\author{
Dr. Ahmed Abdel Azim ElShiekh \\ Alexandria University, Egypt \\ Currently: An Associate Professor of Linguistics \& Translation \\ Zarqa University, P.O. Box. 132014, Zarqa University, Zarqa 13132, Jordan \\ E-mail: shishuj@gmail.com
}

Received: August 25, 2011

Accepted: September 14, $2011 \quad$ Published: February 1, 2012

doi:10.5539/ijel.v2n1p28

URL: http://dx.doi.org/10.5539/ijel.v2n1p28

\begin{abstract}
This paper attempts to explore the problems involved in the Translation of culturally, politically and/or religiously Charged Words and Expressions with particular reference to religion and politics. Most translators and translation scholars are probably familiar with the concept of translation as a major tool used to bridge the gap between different cultures. Nevertheless, is that always the case? Does translation always help bridge the gap, or does it, sometimes at least, widen it, if not even create a new one? With the emergence of modern linguistics in the twentieth century and translation studies a few decades later, a translator was no longer regarded as a creative writer in his/her own right; he/she is basically an honest conveyer of somebody else's message. The more 'invisible' a translator is the better credit he receives. Nevertheless, is this always the case? This researcher discusses the topic with reference to a set of words and expressions of particular interest to the present conditions in the Middle East area.
\end{abstract}

Keywords: Charged words \& expressions, Transfer of meaning versus the promotion of ideology, Ideological considerations, Political motivations, Religious prejudices, The self versus the other

\section{Introduction}

\subsection{In the Beginning ...}

"In the beginning was the Word, and the Word was with God, and the Word was God" (Note 1). The word was also a primary link between the Word as God and Man on the other end. Holy Scriptures and sacred books are a manifestation of the role played by the word in human civilization. Since the confusion of tongues, which is usually thought to have occurred during the days of Peleg, (Note 2) Man has needed a particular group of his fellow men to bridge the gap between one tongue and the other, and to help each and every nation to communicate with other ones. In other words, that was the birth of translation as an indispensible human activity. Whether we take the religious account of the 'confusion of the tongues' as a historical fact or not, the fact remains there; there are many different tongues in the world (Note 3), and translation and translators are necessary for the communication among different nations and different cultures in our world today. Therefore, a close look at the world of translation and translators may serve introduce the topic of this paper and help move forward.

Whenever a professional translator is asked to perform the task of translating a given text in return for a given payment, both the translator and the customer who wants the text in question translated have to worry about the "charge" of the work to be done. Naturally, everybody has to earn his or her living. Professional translators too, have to pay the mechanic, the doctor, the dentist and the milkman whenever they want their everyday needs satisfied. Therefore, in turn, they charge others when they do the job they know best: translate.

This paper, however, is not the least concerned with Charged Translation Tasks, but attempts to explore the problems involved in the Translation of Charged Words and expressions. Most translators and translation 
scholars are probably familiar with the concept of translation as a major tool used to bridge the gap between different cultures. A scholar such as Malinowski even maintains that translation is "the unification of two cultural contexts" (Note 4). Nevertheless, is that always the case? Does translation always help bridge the gap, or does it, sometimes, help create one?

\subsection{Statement of the Problem}

In the good old days, when linguistics had not been born yet, translation studies were no more than a twinkle in the eyes of scholars. They were impressionistic reflections based upon purely personal experience and without any theoretical frameworks to harness the whims and impulses of the writer. Cicero, for instance, who was a pioneer in the field of translation, distinguished between words and their meanings. Nevertheless, he simply maintained that translation was a process of interpreting or embellishing the original text, and claimed the possibility of editing the original in places where it may be redundant, uninteresting or even ambiguous (Note 5). Yet with the emergence of modern linguistics in the twentieth century and translation studies a few decades later, the picture had radically changed. A translator was no longer regarded as a creative writer in his/her own right; he is basically an honest conveyer of somebody else's message. The more 'invisible' a translator is the better credit he receives. The following quotation from Laurence Venuti's The Translator's Invisibility is, indeed, a case in point. "A good translation," he tells us, "is like a pane of glass. You only notice that it's there when there are little imperfections- scratches, bubbles" (Venuti, 2008, p.1) (Note 6). Quite an elegant statement, but can we really take it literally or seriously?

\section{Discussion}

When translation in the early sixties of the twentieth century started to be dealt with not merely as pure art or sheer practice but as a rigorous linguistic discipline under the umbrella of applied linguistics, it was defined as a transfer of meaning. In his pioneering book A Linguistic Theory of Translation (1965), Catford states that translation is the "replacement of textual material in one language (SL) by equivalent textual material in another language (TL)" (Catford, 1965 p. 20) (Note 7).

However, how far is this view of translation still the case in practice? Do translators actually function as neutral objective mediators? Should we even require or expect them to be able to do so? From the transparent pane of glass to Di Giovanni's "writerly approach to translation"(Venuti, 1998: 4) falls translation and "Between the idea and the reality falls" (Note 8) ... the translator!

Translation can be employed as a strategy for the consolidation of the cultural 'Other'. Such a process may not simply involve the fixation of dominant ideologies but also the filtration and blocking of certain autonomous dynamics of cultural representation. (Wolf, 2002)

While traditional academic views generally regard translation as a transparent, impersonal activity which is expected to be blindly faithful to the ideas and meanings of the source text author, contemporary postmodern theories of language have started to recognize the inevitable echoes of the translator's voice in the target language text. At the same time, an increasing awareness of the impact of gender-related issues to the production of meaning and knowledge is beginning to encourage a promising union between feminism, postmodernism, and the emerging discipline of translation studies.

For the literature of one country to be received and appreciated by another, it needs to "pass through" several professional readers, through whom non-professional readers would perceive that literature and that culture. Ideological issues are present throughout the whole decision-making process, from the moment an author or a particular text is selected to be translated, to the point the target text appears in bookstores (Johnson, 2009) (Note 9).

The early 1990s witnessed the emergence of domains in translation studies such as postcolonial translation, ethnographic approaches, or feminist translation. These new approaches have contributed to the redefinition of traditional concepts and have by far consolidated the view of translation as a cultural practice. A few scholars have repeatedly underlined the high degree of social contextualization of translation, even though they have hardly provided a coherent framework for analyzing translation as a social practice. Gouanvic (2007) (Note 10), Simeoni (1998) (Note 11) and Wolf (2007) (Note 12) are cases in point.

Ideological considerations, political motivations and religious prejudices are certainly among the factors that result in the 'visibility' of the traditionally 'invisible' translator. These best manifest themselves when it comes to the translation of heavily charged words and expressions. 
The following is an attempt at reflecting on instances where and when translation, or rather what is "Lost in Translation" (Note 13), sets people apart rather than gets them to communicate properly with each other. A set of examples of the translation/mistranslation of such charged words and expressions may do as an illustration.

To start with, the lexical item 'Charged' in the phrase "Charged words and expressions", according to Merriam-Webster Online, is an adjective that means

"1: possessing or showing strong emotion $<$ attacked the author in a highly charged review $>2$ : capable of arousing strong emotion $<$ a politically charged subject $>$; also : exciting $<$ a highly charged palette of bold colors $>$ " (Note 14).

Another definition presented by Cambridge Advanced Learner's Dictionary provides more or less the same explanation:

"1. (of arguments or subjects) causing strong feelings and differences of opinion or, more generally, filled with emotion or excitement

Abortion is a highly charged issue" (Note 15).

A long list of lexical items such as choice, cancer, scandal, death, freedom, euthanasia, terrorist, beauty, communist, love, hate, change, and betrayal provides us with several handy examples.

A charged word or expression is any word and/or expression that can evoke a strong or powerful emotional response from the reader/listener, a tool often used in media to manipulate public opinions. A case in point is when discussing the issue of abortion: If the addressor is for abortion, you may come across such a statement as: Women have the right to use their own body at will. So, they can abort (implying fetus is their own body). On the other hand, if the addressor is against abortion, one is apt to find the following statement: Children have the right to live, so abortion is bad (implying fetuses are children). In both statements, a "fetus" is not referred to simply as a fetus (Note 16). It is worth noting here that we are still within the same language and/or culture. So how do we expect such linguistic differences resulting from different points of view to be reflected in a translation that is already an attempt to move across different languages and cultures?

A few examples of problematically charged words and expressions have been selected by the researcher, examples that will hopefully be quite representative though, indeed, far from inclusive. The following will hopefully make the point.

Term

Israeli Settlements
Suicidal Attacks

A Secularist State

Radical

$$
\text { تقدمي (يساري) - راديكالي (دون انتماءآت محددة) }
$$

Sometimes even the name of a given place may reflect the problems of heavily charged words. For instance, the holy city for Jews, Christians and Muslims is simply Jerusalem in English. Yet it is referred to in Arabic in three

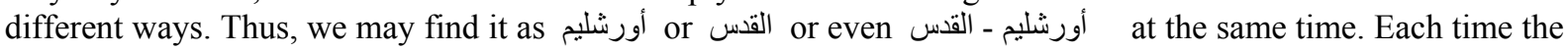
Arabic equivalent changes, the political and ideological stances also do. An Arab Muslim would usually use أورشليم القدس, while a Christian Arab recognizes the two terms; the Holy Bible refers to while Arabic culture with its deeply rooted Islamic foundations prefers أورشليم قاتلة الأنبياء mixture of the two terms in a few cases. Thus, we have the compromise in أورشليم - القنس both together at the same time. The city of peace is no longer a source of peace but escalating conflicts; in politics as well as in translation. According to Hebrew daily Yediot Ahronot, July 13, 2009, Israeli minister of transportation and road safety Yisrael Katz has ordered a change in all Arab names of Palestinian towns and cities that appear on signs on the streets into Hebrew names. The minister was quoted as saying that Jerusalem from now on would be called Yerushalayim and not Jerusalem and in Arabic the word Al-Quds would be erased and instead the word Yerushalayim in Hebrew would be written. He also said that Nasera would be written Nazareth and Akka would be written Akko (Note 17). Thus, translation in this case is not a transfer of meaning but a tool to change the national and cultural identity of the places in question.

Thus the media do not only mirror reality; they also "construct versions of it, and analysis can show how and when certain choices are made- what is excluded/included, foregrounded/backgrounded, made explicit/ implicit, thematized/silenced" (Note 18) (Gambier, Yves, 2006). It is often the case with such "charged" words and expressions that the media deliberately translate them into one way rather than the other so as to manipulate a 
particular reaction on the part of their potential addressee. When a right-wing Israeli newspaper such as Yediot Achronot from Tel Aviv refers to Israeli settlements in the occupied territories in Arabic, it is bound to use the term "swist ", whereas a leftist Israeli newspaper such as Haaretz daily newspaper, in its petition for supporting American President Obama in his committed and persistent leadership in support of a negotiated two-state solution" (Note 19) and in its call to say "Yes! To an Israeli settlement freeze" (Note 20) is more likely to use "مستعمرات" which literally means 'colonies'. Similarly, for years after the Camp David Egyptian-Israeli agreement, the Arabic Egyptian media, such as Ahram daily newspaper and the Egyptian TV Channel One, used to refer to the these settlements as "مستوطنات", literally meaning 'settlements' per se. Yet after the escalating violent confrontations between the Palestinians and Israelis at the onset of the third millennium, the same media started to use the term "مستعمرات" (Note 21). The referent is still the same, yet the linguistic reference changes with the change of political stances even within one and the same newspaper and/or TV Channel programme.

As for the adjective 'suicidal', it is another example of varied and even contradictory translations of one source language lexical item. An attack is simply 'هوم' but when an Islamist such as Fahmi Hwaidi comments on suicidal attacks waged by Hamas or Hezbollah followers, the Arabic term used is "هجمات استشهادية", while an Israeli broadcaster on Israeli television reading the news bulletin in Arabic is bound to use the adjective 'إرهية 'to describe the same action or event. On the Arabic BBC satellite TV Channel, however, the more popular term will probably be 'انتحارية', which is definitely less biassed than the other two. As an academician, I would certainly favour that last expression as an appropriate and faithful rendering of the term 'suicidal' in Arabic. Yet, how often do translators refrain from coloring their targeted texts with their own individual or collective emotions, convictions and ideologies? The researcher has traced ten incidents in which Arabic newspapers in Egypt have reported news of "suicidal" attacks out of which only once the neutral term 'انتحارية ' was used. The rest were unanimously 'إستشهابية', but never 'إسبية'. Yet that was during the period from December 2000 to March 2001. Now in the Summer of 2009, and after the unfortunate serious disagreements between the Egyptian state on the one hand and Hezbollah on the other hand, references to "attacks", whether virtual or actual, waged or to be waged by the Lebanese party, are no longer regarded by the majority of state owned Newspaper and magazines as 'انتحارية'. They are not even regarded as some sort of 'مقاومة' or 'resistance' at all. In fact, this does not only apply to governmental media. Ideological alliances also play their part; Al Ahali newspaper of the Egyptian leftist Tagamo' party has often referred to various activities involving political Islamists as 'terrorist' rather than 'resistance' per se. To go from one extreme to another, Muslim Brothers' media are bound to see the murdering, or shall we say the execution of any 'enemy', as a 'fair and just punishment' of an 'aggressor', be it an Israeli or an Arab anti-Islamist activist such as late Dr Farag Fuda. Dr Fuda was described by secularist thinkers in the Arab world as a 'martyr', but as a deservedly executed 'infidel' by some Islamists in Egypt, including the renowned Sheikh Ghazali. He even testified at court that Dr Fuda deserved to be killed but the problem was only that the execution should have been performed by the ruler rather than an individual citizen.

This last incident may be a good introduction to the problematic translation/translations of the term/s 'secular/secularist' into Arabic. In the first half of the twentieth century up to the mid seventies, there seemed to be no problem translating 'secular' in the phrase 'secular state' into 'علماني/علمانية' as and later into suggested by the late Dr Zaki Naguib Mahmoud in one of his weekly Ahram newspaper articles on Tuesdays (Note 22). With the growing influence of political Islamism, however, the Arabic term has increasingly gained negative connotations among lay persons and has almost become synonymous with 'disbeliever' or 'atheist'. In an attempt to give his own definition of secularism that would persuade the reader to reject it, Fahmi Hwaidi, an eminent Islamist writer in Ahram daily newspaper then, presented in his weekly article published on Tuesday, $6^{\text {th }}$ July, 1986, what he maintained was an accurate translation of the term 'secular' in English as found in Oxford Advanced Learner's Dictionary. The Arabic translation contained the phrase 'التعليم اللا ديني' as a translation of 'non-religious education' implying that a secularist state provides anti-religious education, where the Arabic should have been 'غير مرتبط بالدين' 'غير ديني' 'which would not have been easily confused with 'معادي للادين' as such. With such highly inaccurate representations of the concept of secularism to the Arab reader, the academically accurate translation as 'علماني has almost become derogative. A few secularist thinkers the researcher knows in person, including high-ranking academic figures, refrain from calling themselves or even accepting others to call them 'علماني/علمانيين' for fear of being mistaken by the masses for atheists that should be punished or shall we say 'executed'? A professor of anthropology, quite an enlightened secularist, whether he likes to be called so or not, has recently denied his being 'علماني' on the grounds that the term has become ill-reputed; he asked the researcher to refer to him, in public, as 'علماني' although he is well aware that the latter is equivalent to 'rationalist' rather than 'secularist'. A more popular translation has now become 'مدني/مدنية' which could gain more sympathy in Arab societies as the contrary of 'military', but which remains at least partially a better translation of 'civil' rather than 'secularist'. Thus, the decisive factor in the choice of the Arabic translation of the English term is 
hardly an academic, professional or technical one. The transfer of meaning is sacrificed for ideological, political and/or even social convenience.

Finally, such 'radical' changes in the orientations and sometimes even the very message of the source language utterance are manifested in the translation of the term "radical' itself. It all depends; if it is a leftist stand point, and if the term is used to refer to a leftist thinker or attitude, it is 'تقدمي'. If it is used to describe an Islamist movement or writer, then the translation offered by leftists is 'منطرف/منطرفي' '. Yet if the same term in the source language is to be translated by an Islamist it will probably be 'أصولي' which usually has positive connotations in Arabic. If the translator is neither a leftist nor an Islamist, there is a great possibility the term is translated or rather transliterated into 'راديكالي' which leaves the door wide open for any positive and/or negative interpretations. All is done under the umbrella or more precisely the pretence of 'translation management'. What is lost in translation is thus more significant than what is transferred to the target language and target culture reader. Meanings are twisted and concepts misconceived. The inevitable result is that instead of translation bridging the gap between different cultures, religions and ideologies, translation in reality widens the gap if not even creates a new one.

Other times it is not simply the individual lexical item that causes the problem, but its morphological and/or grammatical status. A classic example is the phrase "Territories occupied" in the Security Council Resolution number 242. Is it simply some أراض محتلة or rather الأراضي المحتلة with a whole world of difference between the two translations or interpretations as such? The result of the deliberately ambiguous English phrase that has, hence, led to the two conflicting translations is a conflict that has not yet been sorted out after 42 years. The Israelis adopt the indefinite reading of the English phrase; they only have to withdraw from some territories that were occupied in the 1967 war. The Arabs, on the other hand, insist that the Arabic translations into الأراضي with the definite article is the right one, especially that the spirit of UN resolutions and major principles in general forbids the annexation of territories by force. Nevertheless, here we are: two different possible translations widening the gap between two political stances rather than bridging it.

The problem is there; but what can or should be done about it? As an academician, one may easily say a translator has to be totally neutral and transparent. However, how far is that a practical or an applicable solution? After all, a translator is but a human being; of flesh and blood. He/she has his/her own affiliations and prejudices. A translator is not simply a mechanical mediator, but a mind and a soul.

The researcher believes, though, that professional exactitude has it that a translator ought to keep to the utmost impartiality possible under human conditions. A translator has to keep to the original source text attitude, conviction and ideological stance. The personal may come up as well but only in the form of a footnote, an endnote or even a detailed preface. In no way is this paper a call to confine translation to a mechanical activity nor reduce the role that can and sometimes ought to be played by translators to a passive one. In fact, the researcher firmly deems that translation should be used as a means to the enlightenment and the progress of any society. The very choice of the text to translate is dictated by the ideological and political convictions of the translator, or at least has to be so. In case the translator has to translate a certain work that contradicts his/her deeply rooted beliefs and attitudes then a preface or an introduction written by the translator can help the translator make his point clear. Managing a translation in a way, for example, to enhance the acceptance of the Other as has been mentioned at the beginning of this research, which is believed by the researcher to be a worthy goal, is certainly permissible, but only provided this is made clear to the reader. There is no pretext whatsoever that justifies the translators' deception or manipulation of the target text reader. Even if the text to be translated involves what the translator believes to be a heresy from his own religious point of view, accuracy comes first. It is almost absurd that all the Arabic subtitles that appear on films broadcast by The Showtime in the Arab region dread to use the Arabic word "الهاله",, and so the word God is always translated into ", even if this may spoil the whole theme of the movie. A striking case in point is, indeed, Jim Carrey's movie Bruce Almighty, in which Morgan Freeman plays the role of God Himself! To quote the well-known traditional Arabic saying: " ناقل الكفر ليس بكافر Therefore a translator's duty is to convey to his/her addressees what the author of the source language piece of discourse intends to convey to his/her readers/listeners. To the researcher, this is almost the sacred duty of the translator per se. At the same time, it is the translator's right, as a human being, to comment on the original, argue against or even refute it as long as his beliefs, convictions, allegiances, ideological or political stances induce him/her to do so. Give what is the author's unto the author and what is the translator's unto the translator.

\section{A Final Word}

Is there a final word? Indeed, like all types of human activities and all disciplines in the realm of humanities, one can hardly reach a definitive conclusion. It is all relative. After all, to quote Peter Newmark, "Nothing is purely 
objective or subjective; there are no cast-iron rules. Everything is more or less" (Newmark, 1981: 21). Perhaps all one can say for sure is that Venuti's pane of glass has turned into a mirror; yet, unfortunately, not one of those mirrors one may have at home; rather one of those funny mirrors one comes across only in Disney Land. In other words, as much as translation can sometimes bridge the gap between different cultures, it can equally widen such a gap, if it does not even, sometimes at least, create a new one on its own.

\section{References}

Primary Sources:

King James Bible, John's Gospel.

Secondary Sources:

Cambridge Advanced Learner's Dictionary. (2008). Cambridge University Press (Electronic Version Produced for CUP by Armada)

Catford, J.C. (1965). A Linguistic Theory of Translation. U.K: OUP.

Conway, Kyle and Bassnett, Susan (ed.) (2006). Translation in Global News. Proceedings of the conference held at the University of Warwick 23 June 2006.

Gardner, Caroline Hoppe. (1977). The Garden and the Sea: A Reanalysis of Trobrland Cosmolog. MA Thesis in Anthropology, PDF Format, University of Southern California, Los Angeles.

Haaretz Daily Newspaper. [Online] Available: http://www.haaretz.com/ (5 Jul., 2009)

[Online] Available: http://ga3.org/campaign/weve_got_your_back_pled ge?qp_sourcehtz_op_s_130x180_stfz (2 Jul., 2009)

[Online] Available: http://www.uruknet.de/?p=m55963\&hd=\&size=1\&l=e (15 Jul., 2009)

Johnson, Penny. Text Selection and the Image of the Other: Translations of Pablo Neruda's Canto. [Online] Available: generalarts.brunel.ac.uk/gate/entertext/4_3/ Johnson_s.pdf (28 Jun, 2009)

Merriam-Webster's Online Dictionary, [Online] Available: http://www.merriam-webster.com/dictionary/ (5 Jul., 2009)

Newmark, Peter. (1981). Approaches to Translation. U.K: Prentice Hall.

Venuti, Laurence. (1998). The Scandals of Translation. London: Routledge. http://dx.doi.org/10.4324/9780203269701

$$
\text { (2008). The Translator's Invisibility. (Second edition), London: Routledge. }
$$

Wolf, Michaela. (2002). Culture as Translation - and Beyond: Ethnographic Models of Representation in Translation Studies, in Theo Hermans, (ed.), Cross-cultural Transgressions: Research Models in Translation Studies II: Historical and Ideological Issues. Manchester: St Jerome.

\section{Notes}

Note 1. King James Bible, John's Gospel.

Note 2. The Old Testament, (Gen. 10:25

Note 3. According to Grimes Ethnologue (1996), the number of languages and/or dialects in the world ranges from 6000 to 8000 ones.

Note 4. Gardner, Caroline Hoppe (1977), The Garden and the Sea: A Reanalysis of Trobrland Cosmology, MA Thesis in Anthropology, PDF Format, University of Southern California, Los Angeles.

Note 5. Newmark, Peter (1981), Approaches to Translation, Prentice Hall. U.K

Note 6. Venuti, Laurence (2008), The Translator's Invisibility, ( $2^{\text {nd }}$ edition) London, Routledge.

Note 7. Catford, J.C. (1965). A Linguistic Theory of Translation. U.K :OUP.

Note 8. T.S. Eliot's famous poem "The Hollow Men". The original line reads:

Between the idea and the reality falls the shadow.

Note 9. Johnson, Penny, Text Selection and the Image of the Other: Translations of Pablo Neruda's Canto general (PDF format) 
Note 10. Gouanvic, Jean-Marc. 2007. "Objectivation, réflexivité et traduction: Pour une re-lecture bourdieusienne de la traduction". In Constructing a Sociology of Translation by Michaela Wolf, Alexandra Fukari - 2007 - Language Arts \& Disciplines

Note 11. Beyond Descriptive Translation Studies: Investigations in Homage, by Gideon Toury, Anthony Pym, Miriam Shlesinger- 2008 - Language Arts \& Disciplines

Note 12. Constructing a Sociology of Translation, by Michaela Wolf, Alexandra Fukari - 2007 - Language Arts \& Disciplines

Note 13. Lost in Translation is a 2003 Oscar Winner movie whose script is written by Sofia Coppola, starring Bill Murray

Note 14. Merriam-Webster Online- http://www.merriam webster.com/dictionary/ charged

Note 15. Cambridge Advanced Learner's Dictionary (20080), Cambridge University Press, (Electronic VersionProduced for Cambridge University Press by Armada)

Note 16. http://forum.wordreference.com/showthread.php?t=163001

Note 17. http://www.uruknet.de/?p=m55963\&hd=\&size $=1 \& \mathrm{l}=\mathrm{e}$

Note 18. Yves Gambier (2006), Transformations in International News" Translation in Global News, Proceedings of the conference held at the University of Warwick, 23 June 2006

(Edited by: Conway, Kyle and Bassnett, Susan), University of University of Turku, Finland.

Note 19. http://ga3.org/campaign/weve_got_your_back_pledge?qp_sourcehtz_op_s_130x180_stfz

Note 20. Haaretz Daily Newspaper, 5 July, 2009, http://www.haaretz.com/

Note 21. It should be noted here that the Arabic مستعمرات in this context is not to be confused with the English term 'colony' or 'colonies'. The idea behind the use of the term مستعمرات is ther underline the fact that the Israeli settlements in question have been built upon occupied 'territories' or 'the territories' occupied in the 1967 war.

Note 22. "الاهرام الثلاثاء 12 أكتوبر (تشرين أول) 1976- "عين - فتحة - عال 